\title{
Author Correction: Characterization of cell fate probabilities in single-cell data with Palantir
}

Manu Setty, Vaidotas Kiseliovas, Jacob Levine, Adam Gayoso, Linas Mazutis and Dana Pe'er

Correction to: Nature Biotechnology https://doi.org/10.1038/s41587-019-0068-4, published online 21 March 2019.

In the version of this article initially published, the link in the Data Availability section was https://prod.data.humancellatlas.org/explore/ projects/29f53b7e-071b-44b5-998a-0ae70d0229a4. This link has become obsolete; the new link is https:/data.humancellatlas.org/ explore/projects/091cf39b-01bc-42e5-9437-f419a66c8a45. The error has been corrected in the HTML and PDF versions of the article.

Published online: 18 September 2019

https://doi.org/10.1038/s41587-019-0282-0

\section{Author Correction: Data storage in DNA with fewer synthesis cycles using composite DNA letters}

Leon Anavy D, Inbal Vaknin, Orna Atar, Roee Amit and Zohar Yakhini (D)

Correction to: Nature Biotechnology https://doi.org/10.1038/s41587-019-0240-x, published online 9 September 2019.

In the version of this article initially published online, a duplicate of the blue and orange boxes containing the percentages in Fig. $4 \mathrm{~b}$ was included in Fig. 4d. The error has been corrected in the print, PDF and HTML versions of this article.

Published online: 16 September 2019

https://doi.org/10.1038/s41587-019-0281-1

\section{Publisher Correction: Your DNA broker}

Laura DeFrancesco and Ariel Klevecz

Correction to: Nature Biotechnology https://doi.org/10.1038/s41587-019-0200-5, published online 16 July 2019.

In the version of this article initially published, LunaDNA was described as a non-profit and a unit of Luna Public Benefit Corporation. "Non-profit" has been deleted and the parent corporation has been changed to LunaPBC, a public benefit corporation. The error has been corrected in the HTML and PDF versions of the article.

Published online: 9 September 2019

https://doi.org/10.1038/s41587-019-0273-1

\section{Publisher Correction: Emerging technologies for improved deep brain stimulation}

Hayriye Cagnan, Timothy Denison, Cameron Mclntyre and Peter Brown

Correction to: Nature Biotechnology https://doi.org/10.1038/s41587-019-0244-6, published online 2 September 2019.

In the version of this article initially published, the direction of the arrows was reversed in Fig. $3 \mathrm{~d}$. The error has been corrected in the HTML and PDF versions of the article. 